\title{
PARTICIPAÇÃO DO SETOR PÚBLICO NA ECONOMIA: UM ESTUDO DE CASO DE PILÕES/RN
}

\section{PUBLIC SECTOR PARTICIPATION IN THE ECONOMY: A CASE STUDY OF PILÕES/RN}

\author{
Camila Oliveira Sousa Santos ${ }^{1}$ \\ https://orcid.org/0000-0003-0337-078X \\ Boanerges de Freitas Barreto Filho ${ }^{2}$ \\ https://orcid.org/0000-0003-1777-3520
}

Submissão: 18/05/2021 / Aceito: 12/08/2021 / Publicado: 23/09/2021.

\section{Resumo}

O objetivo do trabalho é analisar o papel que o Setor Público vem desempenhando na economia de Pilões/RN. O percurso metodológico baseou-se em um enfoque qualiquantitativo e para o levantamento de dados foram utilizados os sites do Tesouro Nacional, Tribunal de Contas do Estado do Rio Grande do Norte, Portal da Transparência do município, dentre outros. Os resultados indicam uma elevada dependência do Setor Público, em que pouco mais de $40 \%$ da população recebe algum tipo de transferência direta e com a Administração Pública respondendo por cerca de 63\% do Valor Adicionado Bruto, no período de 2013 a 2017. Conclui-se que a economia de Pilões/RN tem baixíssimo dinamismo dos setores produtivos e elevado grau de dependência do Setor Público.

Palavras-chave: Dinamismo econômico. Economia municipal. Setor Público. Pilões/RN.

\begin{abstract}
The objective of this work is to analyze the role that the Public Sector has been playing in the economy of Pilões/RN. The methodological path was based on a qualitative-quantitative approach and for the data collection were used the websites of the National Treasury, Court of Auditors of the State of Rio Grande do Norte, Transparency Portal of the municipality, among others. The results indicate a high dependence on the Public Sector, in which just over $40 \%$ of the population receives some kind of direct transfer and with the Public Administration accounting for about $63 \%$ of gross added value, in the period from 2013 to 2017. It is concluded that the economy of Pilões /RN has very low dynamism of the productive sectors and high degree of dependence on the Public Sector.
\end{abstract}

Keywords: Economic dynamism; Municipal economy; Public Sector; Pilões/RN.

\footnotetext{
${ }^{1}$ Bacharela em Ciências Econômicas pela Universidade do Estado do Rio Grande do Norte (UERN). E-mail: coseconomia@gmail.com

${ }^{2}$ Mestre em Planejamento e Dinâmicas Territoriais no Semiárido. Professor do Departamento de Economia da Universidade do Estado do Rio Grande do Norte (UERN), Campus de Pau dos Ferros (CAPF). E-mail: boanergesfilho@uern.br
} 


\section{INTRODUÇÃO}

A partir da crise do Setor Público, nas décadas de 1980 e 1990, muda a presença do Estado no cenário nacional, afastando-se do modelo desenvolvimentista para patrocinar o rentismo da esfera financeira (ARAÚJO, 2000). Nesse sentido, a perda de capacidade do Estado brasileiro em fomentar o desenvolvimento nacional, pautando-se pelo estabelecimento de medidas de política econômica orientadas para buscar/assegurar a estabilidade macroeconômica, constituiu-se no pano de fundo em que Gomes (2001) demonstrou a existência de inúmeros munícipios do Semiárido dependentes das transferências diretas de renda, aspecto que denominou de "economias sem produção".

A característica mais marcante das "economias sem produção" é a elevada dependência de fontes externas de receitas, em que os recursos transferidos para um conjunto de municípios do Semiárido, especialmente, os provenientes do Fundo de Participação dos Municípios (FPM), principal fonte para os pagamentos dos salários dos funcionários públicos, aposentadorias e pensões da Previdência Social e os benefícios pagos pelo Programa Bolsa Família, constituíram-se nos pilares de sustentação dessas economias.

Araújo e Lima (2009) mensuraram o tamanho das transferências diretas para o Semiárido, de modo a atualizar as informações do trabalho de Gomes (2001), com a conclusão de que a "economia sem produção" tinha praticamente dobrado de tamanho em relação ao levantamento inicial feito para o período dos anos 1990. Apesar de tais transferências garantirem uma melhoria nas condições de vida da população e algum alento para as economias municipais, a qualidade de vida da população mais pobre ainda não é das mais satisfatórias e o Semiárido permanece com alguns dos piores indicadores socioeconômicos do país.

A partir de tais delineamentos gerais, tem-se o seguinte o objetivo: analisar o papel que o Setor Público vem desempenhando na economia de Pilões, Rio Grande do Norte (RN).

Além da Introdução, o trabalho foi organizado em cinco seções. A seção 2 aborda os principais delineamentos que caracterizam a chamada economia sem produção. A seção 3 apresenta os procedimentos metodológicos e a delimitação da área do estudo. A seção 4 traz os resultados e discussão e, por fim, tem-se as conclusões do trabalho.

\section{A CHAMADA "ECONOMIA SEM PRODUÇÃO"}

Segundo Gomes (2001), o que desencadeou a "economia sem produção" foram as transformações institucionais do Estado brasileiro, que passou a realizar repasses mais substanciosos de recursos para programas e ações de assistencialismo a partir da década de 1970, coincidindo com o período de expansão acentuada da criação de municípios.

As políticas assistencialistas buscavam compensar a ausência/insuficiência do setor privado nas áreas menos dinâmicas do país, notadamente no interior nordestino, região mais densamente povoada do que o Norte e o Centro Oeste, bem como tentar mitigar as pressões sociais sempre latentes nas áreas mais pobres do Nordeste. Ademais, o Governo Federal se interessava em manter o apoio das oligarquias regionais e um fluxo contínuo de recursos, a fundo perdido, era o meio mais eficiente de alcançar tal propósito (GOMES, 2001).

Os socorros públicos e ações emergenciais para enfrentamento dos períodos de maior escassez hídrica atenderam, em parte, os objetivos pretendidos. O regime militar manteve o apoio político, a partir das bases regionais e locais, mas a miséria e a pobreza continuavam fortemente presentes no cotidiano dos moradores do Nordeste e o quadro social elevava a 
susceptibilidade, de boa parte da população, às intempéries climáticas. Assim, quando as secas ocorriam se ampliava a parcela destinada para assegurar a alimentação da população mais afetada e, em contrapartida, reduzia-se a parte destinada para a realização de investimentos. Em outros termos, pode-se dizer que as verbas repassadas eram suficientes para manter os apoios políticos e alimentar a plebe, mas incapazes de gerar mudanças na estrutura produtiva (GOMES, 2001).

Conforme Gomes (2001, p. 155):

Com efeito, começando com valores bastante altos em 1970, os gastos relativos de investimento público (governo e estatais) no Brasil e no Nordeste despencaram, a partir de meados da década de 80, ao mesmo tempo em que as despesas com pessoal cresceram e as com previdência e assistência explodiram.

A partir de tal constatação, Gomes (2001) aponta as características do que denominou de "economia sem produção", salientando que o Semiárido dispõe de pouca renda e quase nenhum dinamismo produtivo, uma vez que os principais formadores dessa economia seriam os aposentados, os funcionários públicos e os gastos de manutenção da máquina pública realizados pelas prefeituras. Os aposentados se enquadram na "economia sem produção", pois recebem seu benefício sem contrapartida de prestação de serviços produtivos, absolvendo uma parte da renda nacional. Já os funcionários contribuem com prestação de serviço, porém não é suficiente para potenciar as economias locais, e, por fim, as prefeituras que só conseguem funcionar a partir dos recursos transferidos, principalmente pelo Governo Federal, portanto, configurando-se como uma economia com elevada dependência de receitas externas.

\footnotetext{
As transferências de recursos fiscais não são renda de pessoas, embora uma grande parte destas se transforme em tal, vindo a se constituir nos salários dos funcionários municipais prementes e temporários, assim como nos dos empregados das firmas que fornecem bens ou prestam serviços as produções (GOMES, 2001, p. 151).
}

Saliente-se que o marco legal que assegurou a implementação/execução de um conjunto de Políticas Públicas voltadas para a proteção social foi a Constituição de 1988 que, dentre outros aspectos, criou a Seguridade Social e serviu para a elaboração da Lei Orgânica de Assistência Social (LOAS) no início da década de 1990 (TUPY, TOYOSHIMA, 2013).

Conforme Araújo e Lima (2009), o Semiárido recebe quantidade expressiva de transferências se comparadas com seu Produto Interno Bruto (PIB). E os recursos transferidos destinam-se para alguma destas formas de renda: pagamento dos salários dos funcionários públicos, aposentadorias e os benefícios pagos pelo Programa Bolsa Família. A caracterização não é um caso isolado do Semiárido, pois existem áreas por todo o país em que os empregos públicos e os programas de transferência de renda se constituem em elementos econômicos relevantes. Ocorre que a região se diferencia pelo o fato de que essas fontes de renda representam uma parcela considerável do PIB do Semiárido, tornando-se, desse modo, a principal fonte de renda da economia em muitos municípios. E, como essas rendas não possuem, ou possuem pouca contrapartida, pode-se dizer que são os principais elementos característicos da "economia sem produção".

Segundo Vieira (2009), considerando a análise do tamanho do Setor Público por esfera administrativa, verificou-se que em municípios que dispunham de até 5 mil habitantes, o Setor Público era responsável por cerca de $22 \%$ do PIB, já nos municípios com mais de 1 milhão de habitantes era responsável apenas $9 \%$ do PIB. Outra diferença encontrada foi na 
participação das transferências na composição das receitas municipais. De tal modo que, nos municípios com até 5 mil habitantes, as transferências representavam, em média, 93\% da arrecadação total do município. Para os grandes, essa dependência foi de 51,7\%. Ainda de acordo com Vieira (2009), embora os pequenos e médios municípios disponham de alguma capacidade de arrecadação, verifica-se que, para boa parte deles, não é suficiente para que tenham autonomia para manter a máquina pública sem necessitar das transferências dos demais níveis de governo.

Tupy e Toyoshima (2013), afirmam que o termo "economia sem produção" é utilizado para identificar as regiões ou municípios em que as transferências governamentais, como Bolsa Família, Benefício de Prestação Continuada, Aposentadorias Rurais, Empregos Públicos e Transferências Intergovernamentais, são responsáveis por compor a maior parcela da renda regional ou municipal. Logo, as transferências diretas para os cidadãos e aquelas direcionadas para as gestões municipais impactam a renda positivamente, mas em vista de boa parte não exigir contrapartidas dos beneficiários, tem-se como característica geral um produto menor do que a renda.

Com o propósito de verificar a importância das transferências e dos empregos públicos nos municípios integrantes da Microrregião do Jequitinhonha, os autores Tupy e Toyoshima (2013, p. 671) concluíram que:

\begin{abstract}
As transferências diretas de renda correspondem a aproximadamente $27,3 \%$ do Produto Interno Bruto (PIB) dos municípios, sendo que o Programa Bolsa Família atende, sozinho, a mais de um terço da população da região. Nesse contexto, as transferências intergovernamentais correspondem a 94,14\% de todo o orçamento de que as prefeituras dispõem e são mais de 19 vezes superiores à arrecadação de tributos. A administração pública, por sua vez, responsável pela geração de mais de $36 \%$ do total de empregos formais na mesorregião.
\end{abstract}

Os autores constataram a importância das transferências diretas de renda na formação do PIB regional, sendo responsáveis por mais de $1 / 4$ da economia e o PBF alcançando mais de $1 / 3$ da população regional. Apontaram também que as transferências de renda tiveram impactos positivos no produto regional, sobretudo nos setores Agropecuário e no de Serviços, mas sem impactos no Setor Industrial e na geração de empregos formais. Assim, embora haja evidências que tais transferências sejam importantes para reduzir os índices de pobreza e extrema pobreza e, por consequência, promover a melhoria na qualidade de vida dos beneficiários, deve-se observar que não estimulam às atividades produtivas que promovem maior dinamismo (Setor Industrial) e nem impactam a geração de empregos (TUPY, TOYOSHIMA, 2013).

Também existem trabalhos que sinalizam os possíveis efeitos positivos dos gastos públicos para promover maior dinamismo econômico nas áreas receptoras. Por exemplo, Divino e Silva Júnior (2012, p. 507) avaliaram o efeito da composição dos gastos públicos (corrente e de capital) sobre o crescimento da renda per capita dos municípios brasileiros no período 1991 a 2000 e apontaram que: "[os] municípios com renda abaixo da linha de pobreza, definida pelo Banco Mundial ${ }^{3}$, tem uma necessidade maior de gastos correntes do que os que estão acima dessa linha”. Já em relação aos desembolsos de recursos públicos, os autores concluíram que:

\footnotetext{
${ }^{3}$ De acordo com a Organização das Nações Unidas (ONU), o parâmetro de renda obtida para as pessoas que vivem abaixo da linha da pobreza extrema é de até US\$1,90 por dia (DEUTSCHE WELLE, 2018).
} 
Considerando, especificamente, os efeitos da política fiscal, municípios com renda per capita abaixo da linha de pobreza, definida pelo Banco Mundial, conseguiriam aumentar o crescimento econômico ao gastarem mais em despesas correntes do que municípios que estão acima da linha de pobreza. Uma explicação para esse resultado é que municípios pobres almejam crescimento rápido e, para tanto, adotam políticas de investir pesadamente em capital, quando as necessidades da população carente são de curtíssimo prazo. Isto torna o gasto corrente relativamente mais produtivo do que o de capital. Outra explicação é que um município pobre, geralmente, possui atividades econômicas de baixo dinamismo. Nesse caso, os gastos públicos representam importante fonte de renda, gerando empregos e demandando bens e serviços produzidos pelo setor privado. Esses canais elevam a renda local e colocam as despesas públicas como um elemento chave para promoção do crescimento econômico via efeito multiplicador (DIVINO, SILVA JÚNIOR, 2012, p. 525). (Grifo dos autores).

O baixo dinamismo econômico é uma característica de boa parte dos municípios do Semiárido e, de fato, os dispêndios públicos se constituem em importante fonte para movimentação das atividades comerciais e de prestação de serviços básicos. O problema é que esse tipo de estrutura não é suficiente para assegurar a dinamização econômica local.

De acordo com Araújo (2000), no Nordeste, o Setor Público tem maior participação na Formação Bruta de Capital Fixo Total do que na média nacional. Ao investir, produzir, incentivar, criando infraestrutura econômica e social, o Estado se faz presente com grande intensidade na promoção do crescimento da economia nordestina. Assim, a questão que parece fundamental na ação do Estado é o uso que se faz das receitas: priorizando-se investimentos se amplia a capacidade produtiva futura. Já a destinação para custeio de gastos correntes, especialmente nos pequenos municípios, não resulta em mudanças substanciais nas economias.

Observa-se que, Silva Filho e Gledson e Silva (2013), baseando-se em Gomes e Mac Dowell (1995), apontam a insustentabilidade dos pequenos municípios em razão da modesta capacidade de arrecadação e indicam duas prováveis consequências dessa fragilidade fiscal: o conjunto da sociedade acaba por arcar com o financiamento dos gastos em tais áreas e também funciona como estímulo para que grupos oligárquicos utilizem jogadas políticas para criarem esse tipo de município e assim permanecerem no poder. Silva Filho e Gledson e Silva (2013, p. 5) sintetizam a questão nos seguintes termos:

[...] os municípios economicamente pequenos, quase que totalmente dependentes de transferências intergovernamentais, tendem a realizar gastos improdutivos alocando, preferencialmente, suas despesas com funcionalismo público e destinando menos que proporcionalmente, recursos para as áreas sociais [...].

Sabe-se que o comprometimento de grande parte das receitas municipais para pagamento de folha de pessoal foi um dos elementos motivadores para que se estabelece uma limitação dessa despesa na Lei de Responsabilidade Fiscal (LRF). Ademais, as obrigatoriedades de desembolsos mínimos em saúde, educação e assistência social apontam para os usos das receitas. Nessa linha, Silva Filho e Gledson e Silva $(2013$, p. 1) observaram o seguinte sobre a realidade dos municípios do Espírito Santo, para o período de 2001 a 2009:

As principais evidências encontradas mostram que, mesmo diante de um quadro de leve melhora nos indicadores de arrecadação [pós LRF], esses municípios se revelaram essencialmente dependentes de recursos advindos da União Adicionalmente, os resultados mostram redução relativa de gastos em rubricas como despesas com pessoal e legislativo de um ano para o outro. Paralelamente, 
observaram-se maior participação das variáveis, despesas com saúde e saneamento, educação e cultura, dentre outras, para explicar a variação das despesas dos municípios capixabas nos anos observados.

Reconhece-se que a descentralização permite a prestação mais eficaz dos serviços públicos, uma vez que os gestores municipais dispõem de melhores condições para enfrentar os problemas públicos, dando prioridade as questões mais importantes frente à escassez dos recursos para atendimento de todas as necessidades. Assim, o aspecto que parece essencial é a limitação dos recursos, sendo que, nos municípios mais dependentes de transferências, tende-se ao direcionamento do uso das receitas para os gastos correntes em detrimento da utilização para a realização de investimentos, implicando num círculo vicioso de transferências.

\section{PROCEDIMENTOS METODOLÓGICOS E DELIMITAÇÃO DA ÁREA DE ESTUDO}

Quanto aos procedimentos metodológicos, o trabalho consiste em um estudo de caso de Pilões/RN, cuja caracterização socioeconômica se aproxima do padrão existente no interior potiguar, grosso modo, municípios com pequenas populações e baixo dinamismo econômico. Nesse aspecto, o estudo de caso pode servir de referência para estudos comparativos.

A pesquisa teve caráter tanto qualitativo, especialmente quando se fez a discussão do perfil econômico vigente, quanto quantitativo, em que os dados foram coletados, sistematizados e apresentados através de gráficos, tabelas, uso de porcentagens e valores numéricos para facilitar a exposição e compreensão do papel desempenhado pelo Setor Público na economia de Pilões/RN.

A coleta de dados se deu a partir de levantamentos em sites governamentais confiáveis como o IBGE, Secretaria do Tesouro Nacional (STN) no SICONFI/FINBRA, Tribunal de Contas do Estado do Rio Grande do Norte (TCE-RN) e Portal da Transparência do município, entre outros. Também foi realizada pesquisa bibliográfica em autores que tratam dessa temática, tais como Gomes (2001), Araújo e Lima (2009), Araújo (2000), entre outros.

Saliente-se que algumas informações e dados contábeis mais recentes relativos à situação municipal não foram localizados, mesmo após diversas tentativas de buscas feitas nos sites do Tribunal de Contas do Estado do Rio Grande do Norte (TCE-RN), Secretaria do Tesouro Nacional (STN) e Setor de Contabilidade do Prefeitura de Pilões/RN. Já que foi esgotada a possibilidade de obtenção de séries mais longas e recentes de alguns dados, optouse por utilizar a série disponível, constituindo-se, tal situação, em uma limitação da pesquisa.

\section{Delimitação da área de estudo}

O município de Pilões/RN situa-se no Alto Oeste Potiguar e tem sua localização distante 46 km de Pau dos Ferros/RN (via RN 075 e BR 226), ocupando uma área de 82,69 $\mathrm{km}^{2}$, e limita-se (Figura 2) com os municípios de Marcelino Vieira/RN a Oeste, Antônio Martins/RN ao Norte e Alexandria/RN ao Sul e a Leste (IBGE, 2020). 
Figura 2 - Mapa de localização do município de Pilões/RN

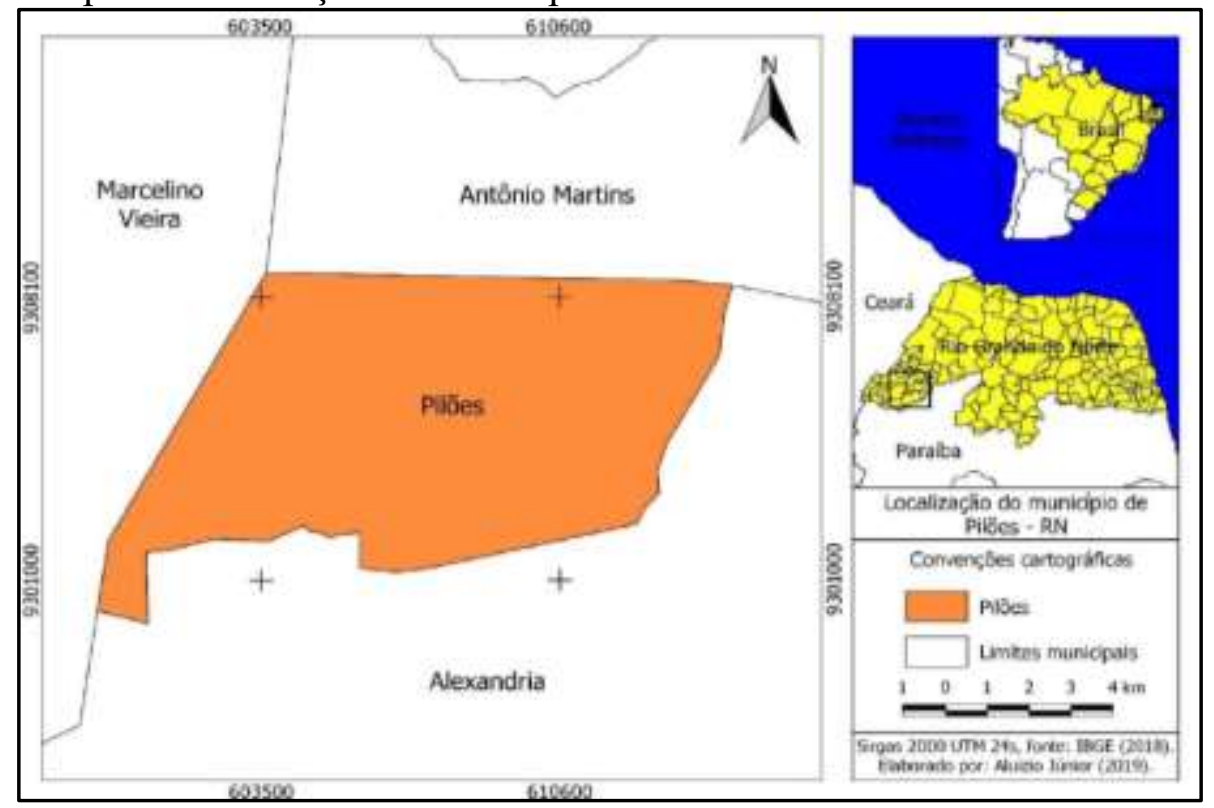

Fonte: Elaboração cartográfica de Bezerra Júnior (2019).

De acordo com o último Censo Demográfico, o município de Pilões/RN apresentava uma população de 3.453 habitantes com densidade demográfica de 41,76 hab. $/ \mathrm{km}^{2}$, sendo 2.533 pessoas residentes na zona urbana e 920 habitantes na rural (IBGE, 2010).

O município de Pilões/RN tem um IDHM de 0,614, inserindo-se na faixa média (IDHM entre 0,600 e 0,699) de desenvolvimento humano. Ao verificar sua evolução nas últimas décadas, entre 1991 e 2010, observou-se que o IDHM cresceu 85\% (PNUD, 2013).

\section{RESULTADOS E DISCUSSÃO}

As características econômicas de Pilões/RN se compatibilizam com os demais municípios da Região Geográfica Imediata de Pau dos Ferros e de boa parte do Semiárido. Tais características principais apontam a existência de atividades econômicas com baixa complexidade, em geral, com preponderância do Setor de Serviços, com comércio, prestação de serviços pessoais básicos e presença marcante do Setor Público na composição do VAB.

Saliente-se que a insuficiência de atividades capazes de dinamizar a economia não se constituíram em óbice para que melhorias sociais ocorressem ao longo das últimas décadas. O Gráfico 1 apresenta os avanços de Pilões/RN a partir do IDHM. 
Gráfico 1 - IDHM de Pilões/RN - variação de 1991 a 2010

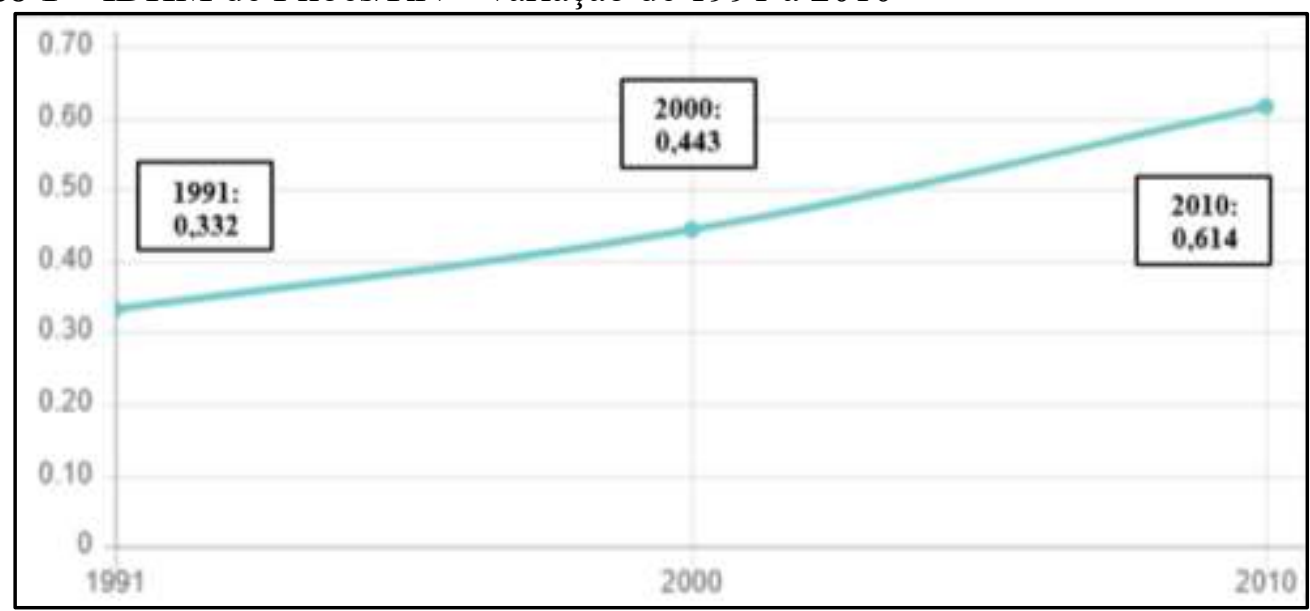

Fonte: IBGE (2013).

O município apresentou em 1991 e 2000 um IDHM baixo (até 0,499), mas melhorando o índice geral e, em 2010, alcançou a faixa de IDHM médio (entre 0,600 e 0,699). Sendo que o componente do IDHM (Renda, Longevidade e Educação) que apresentou melhorias mais acentuadas ao longo do período foi a educação (Ver Tabela 1). Dois aspectos merecem ser destacados: $1^{\circ}$ ) partiu-se de uma situação (em 1991 apenas 0,140) deplorável e $2^{\circ}$ ) mesmo a Educação tendo avançado ao longo do tempo continuou sendo o componente, individualmente, com menor participação no IDHM nos três anos considerados (1991, 2000 e 2010). (PNUD, 2013).

Tabela 1 - Evolução dos componentes do IDHM em Pilões/RN (de 1991 a 2010)

\begin{tabular}{cccc}
\hline Componentes/Dimensões & $\mathbf{1 9 9 1}$ & $\mathbf{2 0 0 0}$ & $\mathbf{2 0 1 0}$ \\
\hline Educação & 0,140 & 0,261 & 0,527 \\
\hline Longevidade & 0,567 & 0,706 & 0,777 \\
\hline Renda & 0,463 & 0,472 & 0,566
\end{tabular}

Fonte: PNUD (2013). Elaboração própria.

O IDHM passou de 0,332 em 1991 para 0,443 em 2000, apresentando uma taxa de crescimento de $33,43 \%$. Nesse período, a dimensão cujo índice mais cresceu em termos absolutos foi Longevidade (com crescimento de 0,139), seguida por Educação e por Renda. De 2000 para 2010, o IDHM passou de 0,443 em 2000 para 0,614 em 2010, apresentando uma taxa de crescimento de $38,60 \%$. Nessa etapa, a dimensão cujo índice mais cresceu em termos absolutos foi Educação (com crescimento de 0,266), seguida por Renda e por Longevidade (PNUD, 2013).

Dados do PNUD (2013) indicam que a renda per capita do município teve um crescimento de cerca 89,45\% nas últimas duas décadas, passando de R\$142,98, em 1991, para R\$150,61, em 2000, e para R \$ 270,87, em 2010. Conforme o PNUD (2013), em 2010, a ocupação das pessoas de 18 anos e maiores era distribuída da seguinte maneira: $18,75 \%$ trabalhavam no Setor Agropecuário, 0,33\% na Indústria extrativa, 4,44\% na Indústria de transformação, 6,05\% no Setor de Construção, 2,40\% nos Setores de Utilidade Pública, $13,96 \%$ no Comércio e 51,95\% no Setor de Serviços.

Segundo o IBGE (2017a), o PIB per capita de Pilões/RN, em 2017, era R\$ 9.143,42, o salário médio mensal era de 1,6 salários mínimos, a proporção de pessoas ocupadas em relação à população total era de 7,1\% (apenas 272 pessoas ocupadas). Levando em 
consideração os domicílios com rendimentos mensais de até meio salário mínimo por pessoa, verificaram-se $50 \%$ da população nessas condições.

O Gráfico 2 apresenta o detalhamento sobre a obtenção de rendimentos mensais obtidos pelas pessoas em Pilões/RN para o exercício de 2017.

Gráfico 2 - Rendimentos mensais obtidos pelas pessoas em Pilões/RN (2017)

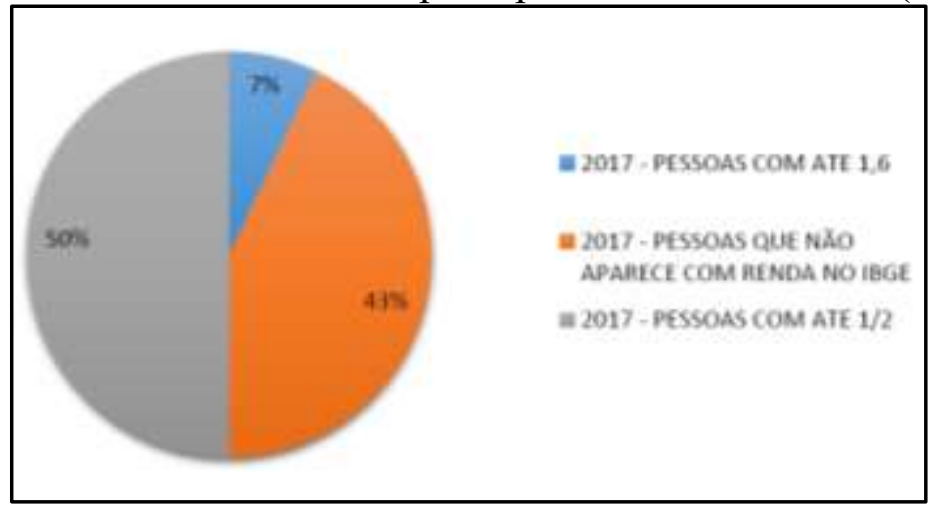

Fonte: IBGE (2017a). Elaboração própria.

Segundo o IBGE (2017a), como demonstrado no Gráfico 2, a população ocupada e que obtinha renda de até 1,6 salário mínimo correspondia apenas a $7,1 \%$, já $50 \%$ da população que dispunha de renda de até meio salário mínimo, enquanto $43 \%$ não dispunha de renda (ressalvando a possibilidade de não terem declarado recebimento de nenhum tipo de renda ou que se recusaram a responder). Tais dados evidenciam a fragilidade da base econômica municipal, posto que não gera ocupações suficientes para absorver a mão de obra e mesmo aquela parcela da população que consegue alguma ocupação tem remuneração muito baixa.

A relevância das transferências diretas aos cidadãos, especialmente Previdência Rural e Bolsa Família, ficou evidenciada pelo montante expressivo de recursos repassados para o município de Pilões/RN ao longo do tempo. O Gráfico 3 apresenta o montante de pagamentos anuais destinados aos beneficiários residentes em Pilões/RN dos exercícios de 2001 a 2017, tendo por referência o mês de dezembro.

Gráfico 3 - Montante de benefícios transferidos pela Previdência Social para o município de Pilões/RN - referência dezembro do período de 2001-2017

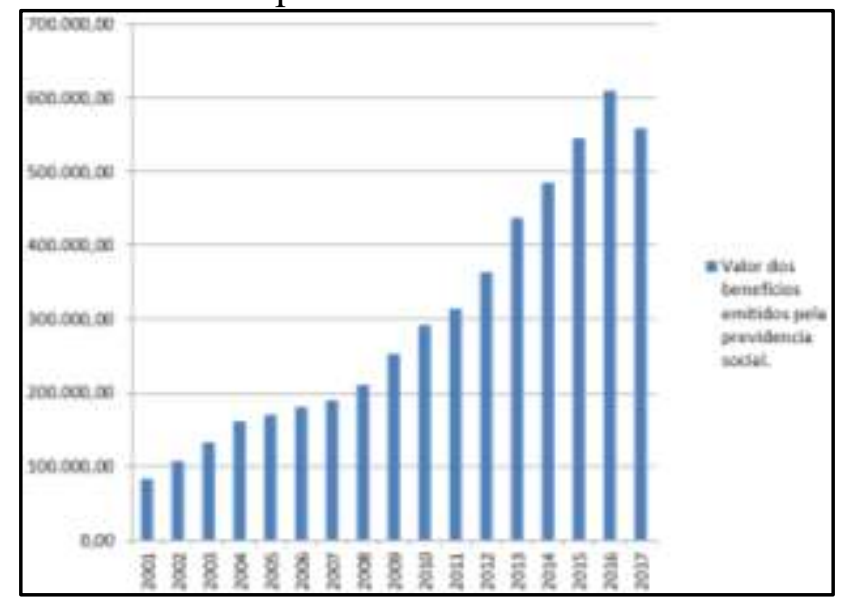

Fonte: Ministério da Economia (2020). Elaboração própria.

DOI: https://doi.org/10.46699/rce.v26i42.6364 Edição Vol. 26, Núm. 42, 2022. 
O montante de pagamentos anuais destinados aos beneficiários residentes em Pilões/RN, via transferências, expostas no Gráfico 3, mostra que em todos os anos, de 2001 a 2017, o montante transferido aumentou, em termos nominais. Apenas em 2017 houve uma redução de tais transferências, sendo decorrente, provavelmente, da diminuição do número de beneficiários (mortes, migração etc.). (MINISTÉRIO DA ECONOMIA, 2020).

Verifica-se que, no primeiro quinquênio (2001 e 2005), o aumento foi de $106,6 \%$ e nos dois quinquênios seguintes (2005 a 2010) e (2010 a 2015), os dois tiveram aumentos superiores a $85 \%$, em função de reajustamentos realizados nos montantes repassados aos beneficiários. (MINISTÉRIO DA ECONOMIA, 2020). Com base nos dados levantados na Secretaria Municipal de Economia, observou-se que, no período de 2011 a 2015, a média de pessoas aposentadas foi de 470 aposentados, verificando-se uma média de aposentadoria por tempo de contribuição de apenas 16 pessoas por ano.

Em relação as transferências diretas para os cidadãos, observou-se que Pilões/RN, em 2019, contava com 934 famílias inseridas no Cadastro Único do município, sendo 508 famílias beneficiárias do PBF no mês de junho e ainda conta com mais 426 famílias que sem o programa estariam em condição de extrema pobreza. (MINISTÉRIO DA CIDADANIA, 2020).

Os montantes expressos na Tabela 2 demonstram a importância social e econômica que as transferências diretas para os cidadãos têm para a socioeconomia de Pilões/RN, sendo fonte de sustento para muitas famílias beneficiadas e assegurando um fluxo constante de recursos para movimentar o comércio e prestadores de serviços diversos.

Tabela 2 - Valores transferidos diretamente para os cidadãos do município de Pilões/RN no período de 2016 - 2019 no Programa Bolsa Família (PBF) e do Benefício de Prestação Continuada (BPC)

\begin{tabular}{ccc}
\hline Ano & $\begin{array}{c}\text { Total anual transferido do } \\
\text { PBF }\end{array}$ & $\begin{array}{c}\text { Total anual transferido do } \\
\text { BPC }\end{array}$ \\
\hline $\mathbf{2 0 1 6}$ & $1.588 .194,00$ & - \\
\hline $\mathbf{2 0 1 7}$ & $1.485 .840,00$ & - \\
\hline $\mathbf{2 0 1 8}$ & $1.147 .269,00$ & - \\
\hline $\mathbf{2 0 1 9}$ & $1.285 .188,00$ & $658.680,00^{4}$ \\
\hline
\end{tabular}

Fonte: Ministério da Cidadania (2020). Elaboração própria.

É evidente a importância socioeconômica do BPC e do PBF, especialmente em realidades como a de Pilões/RN, cuja base produtiva é pouco dinâmica, sendo que a ausência de tais intervenções tenderia a elevar ainda mais os níveis de desigualdades. Saliente-se que as transferências do BPC podem chegar a um salário mínimo, tornando-o capaz de retirar as famílias da indigência e da pobreza (TAVARES et al, 2009).

Embora o PBF não atinja toda a população que se enquadra nos requisitos e nem seja a única solução para a problemática de desigualdade, torna-se importante reconhecer sua indispensabilidade para minimizar a extrema pobreza (TAVARES et al., 2009).

Já sobre as finanças municipais, o Gráfico 4 mostra o montante de repasses de FPM para o município de Pilões/RN, no período de 1999 a 2015.

\footnotetext{
${ }^{4}$ Buscou-se informações referentes aos demais exercícios, mas não foi possível localizar os dados. 
Gráfico 4 - Transferências do FPM para o município de Pilões/RN (1999-2019)

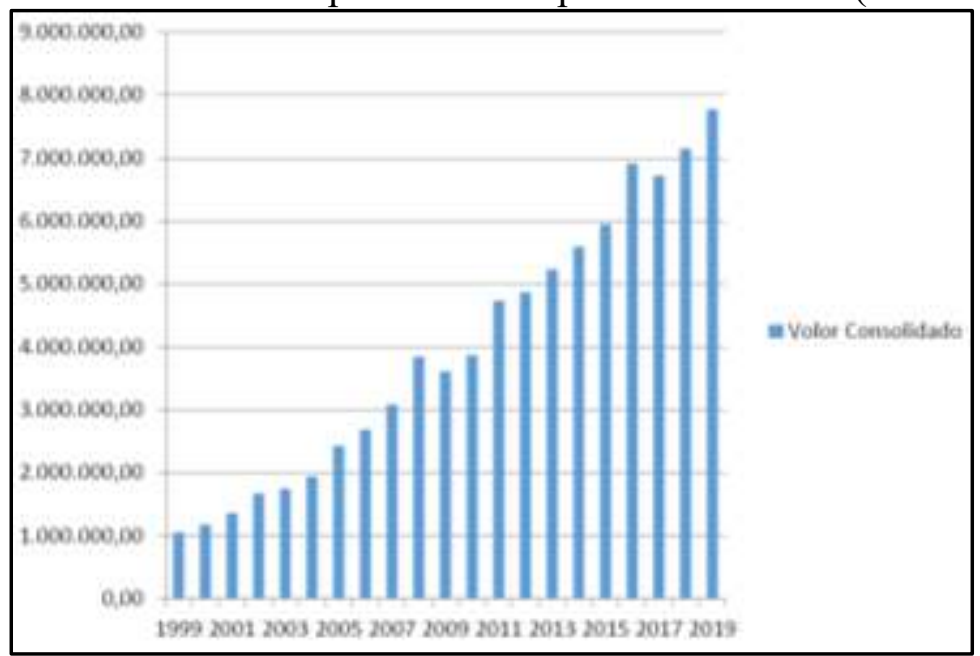

Fonte: STN (2020). Elaboração própria.

No Gráfico 4 observa-se que nos primeiros seis anos (1999 a 2005) ocorreu uma variação de 130,2\% nos repasses de $\mathrm{FPM}^{5}$, em valores nominais. No período de 2005 a 2010 teve um aumento de 59,4\% e de 2010 a 2015 a variação foi de 53,9\%. Em 2016 se observa um crescimento maior dos repasses em relação ao período anterior, aproximando-se de R \$ 7 milhões, apresentando em 2017 leve retração e, novamente, no biênio 2018-2019, voltando a trajetória ascendente, essas variações se devem ao aumento na arrecadação de Imposto de Renda e Imposto sobre Produtos Industrializados que, consequentemente, impactaram positivamente na arrecadação do Governo Federal e nos repasses para as esferas subnacionais.

O Gráfico 5 apresenta os repasses do FUNDEB, de 2007 a 2019, para o município de Pilões/RN. Em 2007 o montante recebido foi de R \$591.811,97, já no ano de 2019 o montante foi de R $\$ 1.850 .555,78$, ou seja, de seu início até 2019, as transferências para o município praticamente aumentaram $212,69 \%$.

Esse crescimento que ocorreu de 2007 para 2019 com uma variação positiva de $212,69 \%$ se deveu ao crescimento do número de alunos cadastrados no município ${ }^{6}$ e aos reajustes concedidos pelo Governo Federal.

\footnotetext{
${ }^{5}$ As variações se devem também as mudanças demográficas apontadas nas estimativas do IBGE do número de habitantes residentes, além de diversas alterações nas porcentagens destinadas aos municípios onde inicialmente se transferia $10 \%$ do IR e do IPI e em 2016 esse percentual foi de $24 \%$.

${ }^{6}$ De acordo com o Instituto Nacional de Estudos e Pesquisas Educacionais Anísio Teixeira - (INEP) as transferências são distribuídas proporcionalmente ao número de alunos informados.
} 
Gráfico 5 - Transferências do FUNDEB ${ }^{7}$ para o município de Pilões/RN (2007-2019)

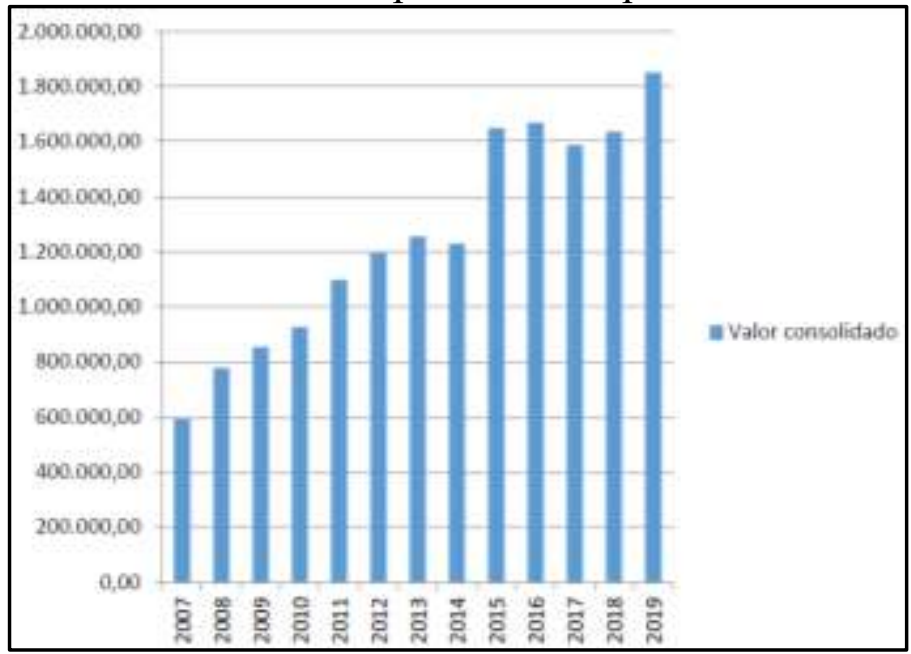

Fonte: STN (2020). Elaboração própria.

O Gráfico 6 apresenta as transferências de Royalties, ou seja, as compensações no resultado da exploração de petróleo ou gás natural, de recursos hídricos e de outros recursos minerais no respectivo território, plataforma continental, mar territorial ou zona econômica exclusiva, realizadas para o município de Pilões/RN para o período de 2000 a 2019.

Gráfico 6 - Transferências dos Royalties ${ }^{8}$ para o município de Pilões/RN (2000-2019)



Fonte: STN (2020). Elaboração própria.

A partir do ano de 2000, o município de Pilões/RN passou a receber os Royalties, conforme o Gráfico 6, inicialmente o repasse em valores nominais foi de $\mathrm{R} \$ 25.648,462000$,

\footnotetext{
${ }^{7}$ A partir de 1998, dos valores do FPM, FPE, IPI-Exportação e ICMS LC 87/96, já está descontada a parcela de $15 \%$ (quinze por cento) destinada ao FUNDEF. A partir 2007, dos valores do FPM, FPE, IPI-Exportação e ICMS Lei Complementar $n^{\circ}$. 87/96 e do ITR, já estão descontados da parcela destinada ao FUNDEB. (STN, 2020).

${ }^{8}$ A partir de 1998, dos valores do FPM, FPE, IPI-Exportação e ICMS LC 87/96, já está descontada a parcela de $15 \%$ (quinze por cento) destinada ao FUNDEF. A partir 2007, dos valores do FPM, FPE, IPI-Exportação e ICMS LC 87/96 e do ITR, já está descontada a parcela destinada ao FUNDEB (STN, 2020).
} 
nos primeiros seis anos o montante teve um crescimento constante, porém nos anos seguintes ocorreram oscilações, atingindo o ápice em 2014, chegando a receber R\$ 152.863,14. Em 2016 teve uma queda e, nos anos seguintes, a tendência foi de crescimento nos montantes repassados devido ao aumento da exploração/prospecção decorrentes da exploração do Présal.

A Tabela 3 demonstra os repasses realizados pelo governo potiguar para o município de Pilões/RN (de 2004 a 2007), destacando-se os montantes relativos aos repasses do ICMS ${ }^{9}$ que se constituem na principal transferência estadual.

Tabela 3 - Repasses do ICMS e outros repasses do estado para o município de Pilões/RN (2004-2007)

\begin{tabular}{ccccc}
\hline Anos & ICMS (RS) & VAR (\%) & TOTAL (R\$) & VAR (\%) \\
\hline $\mathbf{2 0 0 4}$ & 259.539 & - & 284.164 & - \\
\hline $\mathbf{2 0 0 5}$ & 305.706 & 17,79 & 337.864 & 18,90 \\
\hline $\mathbf{2 0 0 6}$ & 364.877 & 19,36 & 394.265 & 16,69 \\
\hline $\mathbf{2 0 0 7}$ & 383.755 & 5,17 & 459.451 & 16,53 \\
\hline
\end{tabular}

Fonte: SET-RN (2010). Elaboração própria.

A Tabela 4 aponta as transferências realizadas para o município de Pilões/RN. O dado não contabiliza os recursos do FPM e do FUNDEB, agregando as demais transferências, com destaque para o montante anual repassado da cota-parte do ICMS ${ }^{10}$.

Tabela 4 - Repasses de outras transferências do estado para o município de Pilões/RN (20082019)

\begin{tabular}{lc}
\hline Ano & Valor Transferido \\
\hline $\mathbf{2 0 0 8}$ & $171.186,81$ \\
\hline $\mathbf{2 0 0 9}$ & $304.652,34$ \\
\hline $\mathbf{2 0 1 0}$ & $202.377,19$ \\
\hline $\mathbf{2 0 1 1}$ & $193.393,06$ \\
\hline $\mathbf{2 0 1 2}$ & $202.529,90$ \\
\hline $\mathbf{2 0 1 3}$ & $337.755,37$ \\
\hline $\mathbf{2 0 1 4}$ & $351.243,16$ \\
\hline $\mathbf{2 0 1 5}$ & $184.010,51$ \\
\hline $\mathbf{2 0 1 6}$ & $174.624,66$ \\
\hline $\mathbf{2 0 1 7}$ & $1.616 .373,23$ \\
\hline $\mathbf{2 0 1 9}$ & $1.755 .270,71$ \\
\hline
\end{tabular}

Fonte: CNM (2020). Elaboração Própria.

$\mathrm{Na}$ Tabela 4, é possível observar que no primeiro quinquênio (2008-2012) houve um crescimento de $18,3 \%$ nas transferências realizadas pelo governo potiguar, já no quadriênio de (2013-2016), diferentemente do que foi visto no primeiro, houve uma queda de aproximadamente $48 \%$, tendo em vista que em 2013 o repasse era de $\mathrm{R} \$ 337.755,37$ e em 2016 de apenas R\$174.624,66.

\footnotetext{
${ }^{9}$ Os repasses específicos da Quota-parte do ICMS referentes aos demais exercícios não foram identificados nos sistemas pesquisados e nem foram repassados pelo Setor de Contabilidade da Prefeitura de Pilões/RN.

${ }^{10}$ A estratégia foi utilizada em virtude das dificuldades para localização dos dados estratificados por fontes. Saliente-se que os dados não estão disponíveis no Portal da Transparência do município, nem foram localizados nas páginas do Tribunal de Contas do Estado e da STN. Sendo ainda solicitados ao Setor de Contabilidade municipal, mas não disponibilizados até o momento da finalização do trabalho.
} 
Outro dado importante observado na Tabela 4 é o salto desse repasse após o ano 2016, em que no triênio seguinte o montante das transferências passa de R $\$ 174.624,66$ em 2016 para R\$ 1.790.517,57 em 2019, ou seja, um aumento de mais de 900\%.

A Tabela 5 apresenta algumas informações obtidas no Relatório Resumido de Execução Orçamentária (RREO), dados consolidados do $6^{\circ}$ bimestre de 2018.

Tabela 5 - Receita prevista, atualizada, realizada no $6^{\circ}$ bimestre e consolidada até o $6^{\circ}$ bimestre - RREO referente ao $6^{\circ}$ bimestre de 2018 - Pilões/RN

\begin{tabular}{|c|c|c|c|c|c|c|c|}
\hline Receitas & $\begin{array}{c}\text { Previsão } \\
\text { inicial }\end{array}$ & $\begin{array}{c}\text { Previsão } \\
\text { atualizada } \\
\text { (a) }\end{array}$ & $\begin{array}{c}\text { No } \\
\text { Bimestre } \\
\text { (b) }\end{array}$ & $\begin{array}{c}\% \\
(\mathbf{b} / \mathbf{a})\end{array}$ & $\begin{array}{c}\text { Até } \\
\text { bimestre } \\
\text { (c) }\end{array}$ & $\begin{array}{c}\% \\
\text { (c/a) }\end{array}$ & $\begin{array}{c}\text { Saldo a } \\
\text { realizar } \\
(\mathbf{a}-\mathrm{c})\end{array}$ \\
\hline Rec. correntes & $17.380 .093,00$ & $17.380 .093,00$ & $2.621 .005,53$ & 15,08 & 13.021.618,18 & 74,92 & $4.358 .474,82$ \\
\hline Imp., taxas e CM & $245.980,00$ & $245.980,00$ & $91.473,66$ & 37,17 & $427.651,09$ & 173,86 & $-181.671,09$ \\
\hline Impostos & $237.196,00$ & $237.196,00$ & 91.197 .76 & 38,45 & $380.888,65$ & 160,58 & $-143.692,65$ \\
\hline Taxas & $8.784,00$ & $8.784,00$ & 239,90 & 2,73 & $46.762,44$ & 532,36 & $-37.978,44$ \\
\hline Transf. Correntes & $17.062 .133,00$ & $17.062 .133,00$ & $2.524 .692,91$ & 14,80 & $12.523 .387,46$ & 73,40 & $4.538 .745,54$ \\
\hline Transf. União & $14.601 .257,00$ & $14.601 .257,00$ & $2.016 .035,75$ & 13,81 & $9.581 .216,93$ & 65,62 & $5.020 .040,07$ \\
\hline Transf. Estados & $606.547,00$ & $606.547,00$ & $220.601,14$ & 36,37 & $1.306 .663,71$ & 215,43 & $-700.116,71$ \\
\hline
\end{tabular}

Fonte: Prefeitura Municipal de Pilões (2019). Elaboração própria.

$\mathrm{Na}$ Tabela 5 é possível observar que as receitas correntes (Impostos, taxas e Contribuições de Melhorias) ou seja, as receitas próprias do município são inferiores ao montante das transferências correntes, União e Estado, logo observa-se facilmente que o município possui elevada dependências de transferências externas. A tabela 5 mostra de forma mais clara essa dependência que o município possui para sua manutenção.

A situação de Pilões/ $\mathrm{RN}^{11}$ pode ser observada na Tabela 6 , em que são apresentados os dados sobre as principais fontes de receitas decorrentes de transferências da União e do Estado, os referentes a Receita Própria, a Receita Total, além de outras informações contábeis relevantes.

Tabela 6 - Receita Própria (RP), Receitas de Transferências Intergovernamentais (RTI), Outras Receitas Correntes (ORC), Receita Total (RT), de 2013-2014 - município de Pilões/RN.

\begin{tabular}{cccccc}
\hline ANO & $\begin{array}{c}\mathbf{1 . ~ R P} \\
\mathbf{( \% )}\end{array}$ & $\begin{array}{c}\mathbf{2 .} \text { RTI } \\
(\mathbf{\%})\end{array}$ & $\begin{array}{c}\text { 3. ORC } \\
(\mathbf{\%})\end{array}$ & $\begin{array}{c}(\mathbf{1 + 2 + 3 )} \mathbf{R T} \\
\mathbf{( \% )}\end{array}$ & $\begin{array}{c}\text { RT/PIB } \\
(\mathbf{\%})\end{array}$ \\
\hline $\mathbf{2 0 1 3}$ & 2,11 & 97,07 & 0,82 & 100 & 37,4 \\
\hline $\mathbf{2 0 1 4}$ & 2,78 & 96,82 & 0,4 & 100 & 35,1 \\
\hline $\mathbf{2 0 1 5}$ & 2 & 96,54 & 1,45 & 100 & 32,78 \\
\hline
\end{tabular}

Fonte: STN/SICONFI (2019). Elaboração própria.

Em 2015, o PIB ${ }^{12}$ foi de R \$32.006.470,00 e a Receita Total foi de R $\$ 10.492 .000,00$. Já em 2014 o PIB foi de R \$29.870.190,00 e a Receita Total foi de R\$10.495.000,00 e, em 2013, o PIB foi de $\mathrm{R} \$ 25.246 .000,00$ e a Receita Total foi de $\mathrm{R} \$ 9.448 .000,00$.

De acordo com a Tabela 6 e com os montantes do PIB, verifica-se que a capacidade de arrecadação municipal foi muito reduzida, aliás, em todo o triênio o desempenho foi modestíssimo, aspecto que aponta a acentuada dependência da gestão em relação as

\footnotetext{
${ }^{11}$ Os dados contábeis apresentados se referem aos exercícios de 2015, 2014 e 2013 em virtude de serem os que estavam disponíveis no sistema STN/SICONFI no período do levantamento.

12 PIB a preços correntes, com série revisada pelo IBGE.
} 
transferências realizadas pelos demais entes da Federação, especialmente os repasses realizados pelo Governo Federal.

Ainda se verifica na Tabela 6 que as Receitas Totais Intergovernamentais correspondem a mais de $95 \%$ da composição das receitas municipais. Tal situação indica que a gestão municipal não tem condições de atender as demandas da população local a partir de sua, quase inexistente, capacidade de arrecadação, constituindo-se em um município altamente dependente de fontes externas de recursos ${ }^{13}$.

Pelo lado das Despesas, a Tabela 7 apresenta os principais dados referentes à situação pilonense. A Despesa Total (DT), em 2015, importou em R\$10.178.000,00. Já em 2014 a DT foi de R\$ 10.856.000,00 e, em 2013, importou em R\$ 9.190.000,00.

Tabela 7 - Composição das Despesas de Pilões/RN no período de 2013 a 2015

\begin{tabular}{cccccccc}
\hline ANO & $\begin{array}{c}\mathbf{1 . ~ O D C} \\
\mathbf{( \% )}\end{array}$ & $\begin{array}{c}\mathbf{2 . P E S} \\
\mathbf{( \% )}\end{array}$ & $\begin{array}{c}\mathbf{( 3 )} \\
\text { DECOR } \\
(\mathbf{\%})\end{array}$ & $\begin{array}{c}\mathbf{4 . ~ I} \\
\mathbf{( \% )}\end{array}$ & $\begin{array}{c}\mathbf{5 . ~ A D} \\
\mathbf{( \% )}\end{array}$ & $\begin{array}{c}\mathbf{( 6 )} \\
\text { DECAP }\end{array}$ & $\begin{array}{c}\text { DT/PIB } \\
(\mathbf{\%})\end{array}$ \\
\hline $\mathbf{2 0 1 3}$ & 45,99 & 54,01 & 95,67 & 69,81 & 30,19 & 4,33 & 36,4 \\
\hline $\mathbf{2 0 1 4}$ & 44,43 & 55,57 & 92,17 & 89,68 & 10,32 & 7,83 & 36,34 \\
\hline $\mathbf{2 0 1 5}$ & 32,68 & 67,32 & 95,1 & 47,3 & 52,7 & 4,9 & 31,80 \\
\hline
\end{tabular}

Fonte: STN/SICONFI (2019). Elaboração própria.

Legenda: ODC - Outras Despesas Correntes; PES - Pessoal e Encargos Sociais; DECOR - Despesas Correntes; I - Investimentos; AD - Amortização da Dívida; DECAP - Despesas de Capital.

As Despesas Correntes (DECOR) apresentaram uma média superior a 94\% no triênio, enquanto as Despesas de Capital (DECAP) tiveram uma média próxima de 6\%. Dos montantes dispendidos com as Despesas Correntes se verificou um dispêndio percentual médio de 59\% com Pessoal e Encargos Sociais (PES), destacando-se a ampliação do gasto com PES ao longo do triênio e chegando a 67,32\% da DECOR no ano de 2015, implicando numa aplicação decrescente, em termos percentuais, para cobertura das Outras Despesas Correntes (ODC), como aquisição de materiais de consumo e contratações de Pessoas Jurídicas (PJ's).

Em 2015 a distribuição percentual das despesas com PES foi a seguinte: vencimentos e vantagens fixas - pessoal civil: $69,88 \%$; obrigações patronais: $12,61 \%$; contratações por tempo determinado: 10,58\%; despesas de exercícios anteriores: 6,91\% e outras despesas variáveis - pessoal civil: 0,01\%. Em 2014: vencimentos e vantagens fixas - pessoal civil: 78,43\%; obrigações patronais: 9,31\%; contratações por tempo determinado: 7,07\%; despesas de exercícios anteriores: 5,1\% e sentenças judiciais: 0,08\%. Em 2013: vencimentos e vantagens fixas - pessoal Civil: $81,8 \%$; obrigações patronais: $4,95 \%$; contratações por tempo determinado: 7,55\%; despesas de exercícios anteriores: 5,23\% e sentenças judiciais: $0,47 \%$ (SICONFI/STN, 2019).

Em 2015 quase $70 \%$ dos gastos com PES foram para pagamento de salários e mais $11 \%$ para pagamento do pessoal contratado temporariamente, ou seja, desembolsos com salários de $82 \%$ do montante destinado para PES. Quando comparado com 2013, com quase $90 \%$, verifica-se uma redução, em termos percentuais, do componente salarial no montante total do PES. Observando-se comportamento distinto das Obrigações patronais, com apenas $4,95 \%$ em 2013 e alcançando 12,61\% em 2015. Isso significa que, em termos percentuais,

${ }^{13}$ Existem muitos trabalhos que sinalizam a incapacidade de sustentação municipal a partir de sua própria arrecadação, tais como Silva Filho, Gledson e Silva (2013); Silva Filho et al. (2009; 2010); Gledson e Silva (2009) e Carvalho (2002). 
maior parcela do PES tem sido recolhida para cobrir as Obrigações patronais e, consequentemente, não se torna renda disponível para os servidores.

Observa-se que a média no triênio de gastos com pagamentos de pessoas e encargos sociais foi de $58 \%$. Esse elevado percentual aponta que resta pouco mais de $40 \%$ para custear as demais despesas do município, tais como saúde e saneamento básico, educação e cultura, o que em longo prazo pode acarretar uma piora geral nas contas municipais, impactando, em última instância, a qualidade dos serviços prestados à população local e, provavelmente, comprometendo ainda mais a capacidade de promoção do desenvolvimento.

A Tabela 8 apresenta informações do Valor Adicionado Bruto (VAB) municipal a partir da participação dos distintos setores e dos Impostos líquidos de Pilões/RN para o período de 2013 a 2017.

Tabela 8 - Valor Adicionado Bruto (VAB) de Pilões/RN e Impostos líquidos (2013 a 2017)

\begin{tabular}{|c|c|c|c|c|c|c|}
\hline Ano & VAB & Agropecuária & Indústria & $\begin{array}{c}\text { Serviços } \\
\text { exclusive } \\
\text { administração, } \\
\text { defesa, } \\
\text { educação e } \\
\text { saúde públicas } \\
\text { e seguridade } \\
\text { social }\end{array}$ & $\begin{array}{l}\text { Administração, } \\
\text { defesa, } \\
\text { educação e } \\
\text { saúde públicas } \\
\text { e seguridade } \\
\text { social }\end{array}$ & $\begin{array}{l}\text { Impostos, } \\
\text { líquidos de } \\
\text { subsídios } \\
\text { sobre } \\
\text { produtos, } \\
\text { a preços } \\
\text { correntes }\end{array}$ \\
\hline 2013 & $24.015,00$ & $\begin{array}{l}746,00 \\
(3,1 \%)\end{array}$ & $\begin{array}{l}818,00 \\
(3,4 \%)\end{array}$ & $\begin{array}{l}7.149,00 \\
(29,76 \%)\end{array}$ & $\begin{array}{l}15.303,00 \\
(63,72 \%)\end{array}$ & $\begin{array}{l}1.230,00 \\
(5,12 \%)\end{array}$ \\
\hline 2014 & $27.914,11$ & $\begin{array}{l}1.736,78 \\
(6,22 \%)\end{array}$ & $\begin{array}{c}901,28 \\
(3,22 \%)\end{array}$ & $\begin{array}{l}8.309,13 \\
(29,76 \%)\end{array}$ & $\begin{array}{l}16.966,91 \\
(60,78 \%)\end{array}$ & $\begin{array}{c}1.956,08 \\
(7 \%)\end{array}$ \\
\hline 2015 & $30.256,29$ & $\begin{array}{c}1.423,54 \\
(4,7 \%)\end{array}$ & $\begin{array}{c}2.243,65 \\
(7,41 \%)\end{array}$ & $\begin{array}{l}7.819,36 \\
(25,84 \%)\end{array}$ & $\begin{array}{l}18.769,73 \\
(62,03 \%)\end{array}$ & $\begin{array}{l}1.750,18 \\
(5,78 \%)\end{array}$ \\
\hline 2016 & $31.348,42$ & $\begin{array}{c}1.376,30 \\
(4,3 \%)\end{array}$ & $\begin{array}{c}920,26 \\
(2,93 \%)\end{array}$ & $\begin{array}{c}8.794,12 \\
(28,05 \%)\end{array}$ & $\begin{array}{c}20.257,74 \\
(64,62 \%)\end{array}$ & $\begin{array}{l}1.516,34 \\
(4,83 \%)\end{array}$ \\
\hline 2017 & $33.763,87$ & $\begin{array}{c}2.070,08 \\
(6,13 \%)\end{array}$ & $\begin{array}{c}661,50 \\
(1,95 \%)\end{array}$ & $\begin{array}{c}9.164,26 \\
(27,14 \%)\end{array}$ & $\begin{array}{l}21.868,04 \\
(64,76 \%)\end{array}$ & $\begin{array}{l}1.310,31 \\
(3,88 \%)\end{array}$ \\
\hline
\end{tabular}

Fonte: IBGE (vários anos). Elaboração própria.

Na Tabela 8 é possível observar que o Setor Privado, no quinquênio de 2013 a 2017, teve uma participação média, aproximada, de 37\%. Já o Setor Público teve uma participação média de $63,18 \%$ no VAB. Esse dado evidencia a acentuada participação do Setor Público na econômica do município.

Por exemplo, para o ano de 2014, imediatamente anterior ao período de maiores dificuldades enfrentadas pela economia nacional (biênio 2015-16), os dados referentes a Pilões/RN indicam uma participação de $29,76 \%$ do Setor de Serviços (considerando também a Administração, saúde e educação públicas e Seguridade Social a participação sobe para 90,5\%), com participação incipiente da Indústria (3,22\%) na composição do VAB e participação modesta do Setor Agropecuário (6,22\%) (IBGE, 2020).

Já em 2017, os dados referentes a Pilões/RN indicam uma participação de 27,14\% do Setor de Serviços (considerando também a Administração, saúde e educação públicas e Seguridade Social a participação sobe para 91,2\%)\%), com redução na participação da Indústria $(1,95 \%)$ na composição do VAB e manutenção da participação do Setor Agropecuário (6,13\%) (IBGE, 2020).

Tais dados comprovam a elevada dependência de fontes externas de recursos (transferências constitucionais, como o Fundo de Participação dos Municípios, e 
transferências diretas aos cidadãos, com destaques para a Previdência e o Programa Bolsa Família) e torna evidente que o município de Pilões/RN se compatibiliza com as características da "economia sem produção".

\section{CONCLUSÕES}

Historicamente o Semiárido brasileiro apresentou elevados índices de pobreza e extrema pobreza, mais ainda, em sua área rural. O padrão regional se manifesta de forma eloquente no RN, cuja área territorial, $95 \%$, encontra-se inserida na faixa semiárida, com municípios de pequeno porte e baixo dinamismo econômico.

Reconhece-se que a regulamentação da CF de 1988 permitiu a institucionalização de políticas e programas, notadamente, nas áreas de saúde, educação, assistência social etc., que contribuíram para a melhoria das condições socioeconômicas da população. Mais recentemente, a partir de 2005, a economia nacional começou a crescer de forma mais vigorosa e o Nordeste, em muitos anos, conseguiu desempenho ainda melhor, repercutindo positivamente na qualidade de vidas das pessoas. Destaca-se que a ampliação da Rede de Proteção Social, a política de valorização do salário mínimo e ações como o Programa Minha Casa Minha Vida (geração de ocupações no setor de construção), dentre outras iniciativas, garantiram maior capacidade de consumo para as famílias, inclusive aquelas situadas na base da pirâmide social.

Saliente-se que, ao longo do período de 2002 a 2012, a economia potiguar cresceu acima da média regional, sugerindo que o ritmo de crescimento estadual tem elevada dependência da conjuntura nacional. Ademais, o ciclo de expansão permitiu melhorias na infraestrutura, além de impactos positivos nos indicadores socioeconômicos do estado. A partir de meados da segunda década do século XXI, em decorrência de uma conjuntura econômica e política cada vez mais conturbada, observa-se a acentuada deterioração das finanças estaduais, perda de capacidade de investimento, desaceleração nas melhorias socioeconômicas conquistadas e piora das condições produtivas, destacando-se a política de desinvestimentos praticadas pela Petrobrás na Bacia Petrolífera Potiguar. Acrescente que o longo período de estiagem (2012 a 2017) comprometeu ainda mais a capacidade produtiva do combalido Setor Agropecuário.

Percurso similar pode ser descrito para boa parte dos municípios potiguares, beneficiando-se na fase de crescimento econômicos do país, da região e do estado, com impactos positivos provenientes de maiores repasses de recursos, implementação de inúmeras Políticas Públicas, mas também sofrendo as consequências da reversão do crescimento, da deterioração da capacidade fiscal e também provenientes da seca (20122017), com desdobramentos ainda em curso.

Em relação à economia de Pilões/RN, verificou-se que o salário médio mensal era de 1,6 salários mínimos, a proporção de pessoas ocupadas em relação à população total era de $7,1 \%$ (apenas 272 pessoas ocupadas) e $50 \%$ da população residia em domićlíos com rendimentos mensais de até meio salário mínimo por pessoa. A configuração geral da economia pilonense aponta para a elevada dependência do Setor Público, isso por que o Setor Privado é composto por pequenos negócios, muitos dos quais não formalizados, incipiente participação do Setor Industrial na composição do VAB, Setor Agropecuário também muito modesto e ainda afetado pela longa estiagem de 2012 a 2017, um Setor de Serviços (exclusive Administração Pública) que oferta apenas serviços pessoais básicos. 
Com base nos dados e informações reunidos nessa pesquisa é possível afirmar que o perfil econômico existente em Pilões/RN se compatibiliza com a chamada "economia sem produção" proposta por Gomes (2001) e também com o que foi evidenciado no trabalho de Araújo e Lima (2009). Ficou evidenciado que o Setor Público desempenha papel central na economia pilonense, pois a manutenção da máquina pública municipal, assim como as transferências repassadas diretamente para os cidadãos, constituem-se nos sustentáculos da economia local.

\section{Referências}

ARAÚJO, Leonardo Alves de; LIMA, João Policarpo R. Transferências de renda e empregos públicos na economia sem produção do semiárido nordestino. Planejamento e políticas públicas, 2009.

ARAÚJO, Tânia Bacelar de. A “questão regional" e a "questão nordestina”. In: TAVARES, Maria da Conceição (Org.) Celso Furtado e o Brasil. São Paulo: Editora Fundação Perseu Abramo, $2000 . \quad$ Disponível em: http://www.ifibe.edu.br/arq/201507272115271743262037.pdf\#page=75. Acesso em: 02 fev. 2021.

CARVALHO, Ailton Mota de. Estado, descentralização e sustentabilidade dos governos locais no Brasil. Economía Sociedad y Territorio, 2002.

CONFEDERAÇÃO NACIONAL DOS MUNICÍPIOS (CNM). Transferências. 2020.

Disponível em: https://www.cnm.org.br/municipios/transferencias. Acesso em: $08 \mathrm{fev}$.

2020.

COSTA, Liduina Farias Almeida. Revisitando a Questão do Nordeste: representações de uma região-problema. Políticas Públicas e Sociedade, v. 1, n. 1, 2001.

DEUTSCHE WELLE. Mundo: quase metade da população global vive abaixo da linha da pobreza. 2018-10-18. Disponível em: https://www.dw.com/pt-br/quase-metade-dapopula $\% \mathrm{C} 3 \% \mathrm{~A} 7 \% \mathrm{C} 3 \% \mathrm{~A} 30-m u n d i a l-v i v e-a b a i x o-d a-l i n h a-d a-p o b r e z a / a-45933653$. Acesso em: 5 fev. 2021.

DIVINO, José Angelo; SILVA JUNIOR, Rogério Lúcio Soares da. Composição dos gastos públicos e crescimento econômico dos municípios brasileiros. Revista Economia, v. 13, n. 3, p. 1-22, 2012.

GLEDSON E SILVA, William. Finanças públicas na nova ordem constitucional brasileira: uma análise comportamental dos municípios potiguares, nos anos antecedentes e posteriores à lei de responsabilidade fiscal LRF. 2009. 131 f. Dissertação (Mestrado em Economia Regional) - Universidade Federal do Rio Grande do Norte, Natal, 2009. Disponível em: https://repositorio.ufrn.br/jspui/handle/123456789/14061. Acesso em: 21 jan. 2021.

GOMES, Gustavo Maia. Velhas secas em novos sertões: continuidade e mudanças na economia do semi-árido e dos cerrados nordestinos. Rio de Janeiro: IPEA, 2001.

INSTITUTO BRASILEIRO DE GEOGRAFIA E ESTATÍSTICA (IBGE). Produto Interno Bruto dos Municípios. Pilões/RN. 2017a. Brasil. Disponível em: https://cidades.ibge.gov.br/brasil/rn/piloes/pesquisa/38/46996?ano=2017. Acesso em: 07 mar. 2021.

INSTITUTO BRASILEIRO DE GEOGRAFIA E ESTATÍSTICA (IBGE). Censo Agropecuário. 2017b. Brasil. Disponível em: 
https://censos.ibge.gov.br/agro/2017/templates/censo agro/resultadosagro/index.html.

Acesso em: 07 mar. 2021.

INSTITUTO BRASILEIRO DE GEOGRAFIA E ESTATÍSTICA (IBGE). Panorama Pilões/RN. [vários anos]. https://cidades.ibge.gov.br/brasil/rn/piloes/panorama. Acesso em: 29 mar. 2021.

INSTITUTO BRASILEIRO DE GEOGRAFIA E ESTATÍSTICA (IBGE). Censo

Demográfico. 2010. Brasil. Disponível em:
https://cidades.ibge.gov.br/brasil/rn/piloes/pesquisa/23/27652?detalhes $=$ true.. Acesso em: 07 mar. 2021.

INSTITUTO BRASILEIRO DE GEOGRAFIA E ESTATÍSTICA (IBGE). Índice de Desenvolvimento Humano de Pilões/RN. 2013. Brasil. Disponível em: https://cidades.ibge.gov.br/brasil/rn/piloes/pesquisa/37/30255?tipo=grafico. Acesso em: 07 mar. 2021.

MINISTÉRIO DA CIDADANIA. Bolsa Família e Cadastro Único no seu Município. $2020 . \quad$ Disponível em: https://aplicacoes.mds.gov.br/sagirmps/bolsafamilia/relatorio-completo.html. Acesso em: 31 jan. 2020.

MINISTÉRIO DA ECONOMIA. Estatísticas Municipais 2000 a 2017. 2020. Disponível em: https://www.gov.br/previdencia/pt-br/acesso-a-informacao/dados-abertos/previdenciasocial-regime-geral-inss/estatisticas-municipais-2000-a-2016. Acesso em: 04 fev. 2020. PREFEITURA MUNICIPAL DE PILÕES. RREO - Relatório Resumido da Execução Orçamentária - 2018. 2019. Disponível em: https://www.piloes.rn.gov.br/lrf.php. Acesso em: 06 fev. 2020.

PROGRAMA DAS NAÇÕES UNIDAS PARA O DESENVOLVIMENTO (PNUD). Atlas do Desenvolvimento Humano no Brasil. Perfil de Pilões/RN. 2013. Disponível em: http://www.atlasbrasil.org.br/perfil/municipio/241000. Acesso em: 20 jan. 2021.

SECRETARIA DE ESTADO DA TRIBUTAÇÃO DO RIO GRANDE DO NORTE (SETRN). Repasses por municípios do RN. Pilões/RN. 2010. Disponível em: http://www.set.rn.gov.br/contentProducao/aplicacao/set v2/arrecadacao/enviados/FPM/ind ex.html. Acesso em: 04 fev. 2020.

SECRETARIA DO TESOURO NACIONAL (STN). Transferências Constitucionais. 2020. Disponível em: https://sisweb.tesouro.gov.br/apex/f?p=2600:1::MOSTRA:NO:RP::. Acesso em: 23 jan. 2020.

SECRETARIA DO TESOURO NACIONAL (STN). Sistema de Informações Contábeis e Fiscais do Setor Público Brasileiro (SICONFI). 2019. Disponível em: https://meumunicipio.org.br/perfil-municipio/2410009-Piloes-RN?exercicio $=2015$. Acesso em: 06 de fev. 2020.

SILVA FILHO, Luís Abel da; GLEDSON E SILVA, William. Considerações acerca das finanças públicas municipais no estado do espírito santo: 2001/2009. Anais do VI Seminário Internacional sobre Desenvolvimento Regional: Crises do Capitalismo, Estado e Desenvolvimento Regional. Santa Cruz do Sul/RS: UNISC, 2013. Disponível em: http://www.unisc.br/site/sidr/2013/Textos/294.pdf. Acesso em: 21 jan. 2021.

SILVA FILHO, Luís Abel da et al. Considerações sobre receitas municipais em estados do Nordeste brasileiro: uma análise comparativa referente ao comportamento da arrecadação 
dos municípios baianos, cearenses e piauienses, no ano de 2007. Seminário Internacional sobre o Desenvolvimento Regional do Nordeste, 2009.

SILVA FILHO, Luís Abel da et al. Receitas Correntes em Municípios Cearenses: Autonomia ou Dependência?. Revista Controle: Doutrinas e artigos, v. 8, n. 1, p. 403-421, 2010. TAVARES, Priscilla Albuquerque et al. Uma avaliação do programa bolsa família: focalização e impacto na distribuição de renda e pobreza. Pesquisa e Planejamento Econômico (PPE), v. 39, n. 01, p. 25-58, abr. Rio de Janeiro: IPEA, 2009. Disponível em: http://repositorio.ipea.gov.br/bitstream/11058/5122/1/PPE v39 n01_Avaliacao.pdf. Acesso em: 31 jan. 2020.

TUPY, Igor Santos; TOYOSHIMA, Silvia Harumi. Impactos dos programas governamentais de transferência de renda sobre a economia do Vale do Jequitinhonha. Revista Econômica do Nordeste, v. 44, n. 3, p. 671-692, 2013.

VIEIRA, Roberta da Silva. O tamanho do setor público no contexto do federalismo: Um modelo aplicado aos municípios brasileiros. Texto para Discussão, No. 1415. Brasília: Instituto de Pesquisa Econômica Aplicada (IPEA), 2009. Disponível em: https://www.ipea.gov.br/portal/images/stories/PDFs/TDs/td 1415.pdf. Acesso em: 02 fev. 2021. 